\title{
English Language Teaching At The Primary Level: Foundations For Bilingualism Or Not?
}

Rachel Lalitha Eapen, Sultan Qaboos University, Oman

\begin{abstract}
In countries where English is a second language, there has been a movement over the last 60 years from supporting indigenous languages over foreign language - English - to the present one where, with globalization and market demands, English is beginning to be seen as an indigenous language in itself. The teaching of English from Grade 1 about five years ago points to this change in India. The consequences of such a shift for language acquisition at the primary level is a matter of concern, however, when English is not the first or second language of the people, but is the medium of education, and when the average classroom teacher at the primary level is inadequately prepared for the task. The gaps in the teacher's preparation and the coping strategies she employs are discussed in this paper in order to identify teacher resistances to new books and methodologies. Resistances can be seen to serve as areas for growth according to the constructivist perspective of a Bakhtinian dialogue and a collective articulation of a ZPD, described by Vygotsky, for syllabus design. The syllabus, when it emerges in this way, can be taken to be valid in terms of relevance and to serve as appropriate comprehensible input necessary as the first step for development and change for in-service primary school teachers teaching new texts set in new curricula. Classrooms in three schools in India were visited from which a syllabus outline for an in-service primary school teachers evolved. Teacher practice and resistances are analysed against larger questions, such as: What does such teacher orientation imply for linguistic development of a second language on the whole and for the cognitive development of the child? Would semi-lingualism be encouraged or would we have basic foundations for effective bilingualism?
\end{abstract}

Keywords: Bilingualism; Semi-Lingualism; Curriculum; ZPD; Dialogue

\section{INTRODUCTION}

lobalisation has brought changes to educational systems all over the world on a large scale. India, where English is a second or third language and which is already reaping dividends as one of the largest Englishspeaking countries in the world, has taken steps to equip the young in specific ways, one of which is to introduce English as a subject and even medium, as partial or complete immersion from kindergarten onwards. Whereas indigenous languages have had emotional and partisan support over English in the past 60 years since it gained independence from the British, there is a clamour for English today, reflecting a change of ownership of the language, if you like, moving the boundaries of the 'extended' and 'outer' circles of language use into inner circles (Kachru, 2001). Academic decisions take a new shape when a global language like English is being considered in this post colonial framework (Viruru, 2001). The consequences of teaching English from Grade 1 is a matter of academic concern, however, when the linguistic home environment is not necessarily an English-speaking one (so that English is often the third, rather than even a second language) and when the average classroom teacher at the primary level is inadequately prepared for the task. Therefore, the introduction of such policies might affect both second and first language development and cognitive development as well. Would semi-lingualism be encouraged or would we have basic foundations for effective bilingualism? Further, what are the gaps in teacher preparedness and the steps they take to 'cope' with problems encountered? These questions are discussed in this paper with data taken from three government schools in south India. 


\section{BACKGROUND}

Studies in bilingualism claim that learning a second language before the first has been acquired could lead to a 'dual semi-lingualism' with negative cognitive effects (Skutnabb-Kangas, 1984; Skutnabb-Kangas and Toukomma, 1976; and Cummins, 1979). The Interdependance Hypothesis described by Cummins (1979) shows, moreover, that a verbal and literary grounding in the first language would have positive spin-offs for the second language as well, bringing about more concept clarity and objectification with the appearance of a second threshold level of proficiency in bilingualism - a characteristic of additive bilingualism. Another interesting claim is that the second language leads to the development of the first and to the development of thought and cognitive processes in general. The distinction, moreover, between BICS (Basic Interpersonal Communicative Skills) and CALP (Cognitive Academic Language Proficiency) puts the onus of thought and cognitive development on schooling and academic-based language development. Cummins shows how this assertion can be theoretically supported by Vygotsky's distinction between spontaneous and scientific concepts, whereby scientific concepts can model the spontaneous ones rather than the other way around, giving support to the fact that the second language can promote development of the first. Further, a delay of the onset of a second language is helpful, it seems, for consequent cognitive development which would promote many benefits, such as multitasking and a delay of old age problems like Alzheimer's (Bialystock, 2009). The timing, therefore, of when the first language starts seems to be crucial.

In spite of what research has to say about the onset of the second language in relation to the first, and in spite of the importance of the first language for cognitive development, however, the race for equipping the young for life has continued with speed in India, as indeed in many countries, with the introduction of L2 or English from Grade 1. This has been done even while acknowledging that 'prevailing academic opinion' contradicts this early introduction of L2. The decision had been made in India, as early as 2005, to introduce L2 in Class 1 by an Act of Parliament. The National Curriculum Framework - NCF - (NCERT, 2005) in India says in promoting English in class I:

While endorsing prevailing academic opinion for a later but more effective introduction of English (supporting this with an assessment of the "critical period" or "sensitive window" hypothesis . . .), we also respond to current realities by describing what is achievable in given situations, supplemented with affirmative actions where necessary. (Executive Summary and Recommendations, National Focus Group on English. Position paper, 2005, p. ii)

'Current realities' are pressing market needs, parent pressure and the response of politicians to the situation. In his study, English Next, India, Graddol (2010) quotes Mohanty:

English is gradually being moved to Grade 1 regardless of the fact that it has been shown in India ... that it isn't required. It's more ... Ministers of Education competing with each other to cater to the popular demands - the uninformed choices of people. (p.119)

The rush to English in primary schools has its dangers, one of which is the widening of social gaps that already exist in Indian society according to Graddol (2010). He adds that although India matches China in terms of size and complexity in population and economy, it differs by having a different colonial past and by its emphasis on human capital, as opposed to China's focus on natural resources (e.g. oil) or low-cost labour (manufactured exports) (p.112). In addition, the fact that India has the largest number of young in the world today (21\% to China's $14 \%$ ), coupled with the fact that out of 250 million plus children going to school, 188 million are in the primary classes (with a large dropout rate at the secondary level because of failure - not surprisingly - in English and Math), points to a problem that is gargantuan in nature and not to be ignored by policymakers. English can be taught and learned differently in different educational environments.

There could be large cognitive deficits or 'water lilies without roots' as Skutnabb-Kangas says. Deficits of language and cognition in such large numbers is one thing, but the other side of the coin is the six million or so primary school teachers who are 'at sea' as a consequence of new policies on how to cope with new requirements. The widening of social gaps is intensified because teachers are ill-prepared for the task of starting English in Grade I. This was true in 2005 when the new policy came into being and it appears to be the same condition today. Graddol gives data based on the recommendations of Cambridge University, UK, which puts the minimum language 
requirement for an English teacher to be B1. In fact, teachers are "below the level expected by an undergraduate student studying in English, which is usually taken to be C1". He adds:

In 2009, the British Council was asked by the Tamil Nadu government to test the speaking skills of a group of upper primary teachers prior to a training programme. The teachers were required to have a BA or equivalent in English and to have undergone earlier training, so the group cannot be regarded as representing the general range of teachers. Most of the group reached the B1 threshold, but few reached C1. (Graddol, 2010, p.94) (my emphasis)

Indeed, teachers of younger age groups are less qualified than other teachers with a lower level of education and proficiency in English than secondary teachers.

Although the context described by the bilingual hypotheses is within an immigration context, there are similarities to a second language teaching situation in an ex-colonial set-up that are close enough not to ignore. While eschewing the reactionary overtones of developing a mother tongue, we still need to ask the question whether the globalisation of English and the starting of it in early stages of school will affect language production so that what emerges might be a 'new' English Graddol (2005). How could this happen?

At every level of curriculum implementation and planning, there is a watering down of objectives and goals. For example, the objectives in the NCF (2005) documents are, as objectives and goals often are, unrealistic and unattainable. Although the question posed by the NCF, in relation to English Language development, was "How do we develop English without loss of the mother tongue and first language?", the accompanying recommendations in the document itself, for the teacher and for curriculum and materials production, are not helpful or hopeful as a valid solution for effective bilingualism in the long run.

For example, while the NCF (2005) recommends that teachers should have proficiency in English and that teachers should have teaching methodology of language skills based on the principles of teaching and learning language, the data on the ground shows that many 'shoulds' do not actually exist as expected. This is true of the claims for evaluation and curriculum as well. The discussion on curriculum implementation, however, continues, with the blame being laid at various doors but the actual place where it should be placed. The fact that millions of schools are functioning and millions of teachers are practicing, the suggestion here is not to upset the applecart or throw the baby out with the bath water, but to take more realistic steps, which trajectory seems to be the only solution left for consideration.

\section{What are these realistic steps?}

In our visits to schools, it was evident that there is a large gap between what is expected and what is actually happening. Teacher preparation is severely underestimated and addressed. Meetings with teachers at the government schools yielded several gaps between expectations and reality. We observed that the teacher is functioning as best as s/he can in the face of a situation that is completely new.

While these gaps do exist, however, we can see that the teacher 'copes' with whatever skills and resources she has to overcome them. The resulting actions might or might not be detrimental for the learner when teachers function with a 'hit or miss' attitude. Teachers, moreover, have resistances to new ideas. This is not to say that a minute planning and prescription for teacher behaviour is advocated, but rather that there should be more accountability when new proposals are implemented. When identified, however, resistances and difficulties of teachers can be seen as areas where there might be more growth since there is active involvement in held beliefs. Resistances can, in other words, be turned into a productive co-construction of meaning because it carries with it emotional investment.

What do teachers do to cope? When teaching practice is seen in the light of notions, like ZPD or the zone of proximal development and perezhivanie ${ }^{1}$, or lived or emotional experience of teachers' awareness of their students' emotional and cognitive lives, when there is interthinking and intermental and intramental activities (Mercer, 2000), elaborations can throw up an emergent syllabus. We move from what teachers actually do (strategies) to an examination of what they could do. This insight can come through dialogue as this paper illustrates. Such dialogue is a 'bottom-up' approach to language, and teacher's cognitive development is probably a solution where implementation has begun without adequate preparation and training. Rather than start with a 'top- 
down training programme, a bottom-up beginning takes practicing teachers on board.

\section{FINDINGS}

In our study conducted among teachers with the introduction of the new Marigold Readers, based on the NCF and published by NCERT, we made several observations. A list of the major gaps and resistances of teachers to the new curriculum were identified together with the strategies used by them (see Table 1).

Table 1: The Major Gaps and Resistances of Teachers and the Strategies used by Them

\begin{tabular}{|l|l|l|}
\hline \multicolumn{1}{|c|}{ Gaps } & \multicolumn{1}{c|}{ Strategies Used By Teachers } \\
\hline 1 & Language deficits & Have the right attitude with confidence and fluency. Use whatever language is available. \\
\hline 2 & $\begin{array}{l}\text { Lack of knowledge of claims } \\
\text { of the syllabus. }\end{array}$ & $\begin{array}{l}\text { In the event of uncertainty and doubt, even ignorance, build bridges with whatever is at } \\
\text { hand }\end{array}$ \\
\hline 3 & $\begin{array}{l}\text { Teachers' perception of } \\
\text { language. }\end{array}$ & Language is a subject, not a medium. \\
\hline 4 & $\begin{array}{l}\text { Teachers' perception of } \\
\text { language teaching at the early } \\
\text { stages }\end{array}$ & Language is literacy. Memorization of as much language as possible. \\
\hline 5 & $\begin{array}{l}\text { The classroom environment } \\
\text { Accountability to stakeholders }\end{array}$ & $\begin{array}{l}\text { Teach in structured classroom systems; teacher fronted classes are most manageable; } \\
\text { Language learning means serious application and work. }\end{array}$ \\
\hline 7 & $\begin{array}{l}\text { The role of the textbook in } \\
\text { language education. }\end{array}$ & $\begin{array}{l}\text { Depend on the textbook as the only source of language. It is easy and safer, just in case } \\
\text { teachers are called to account. }\end{array}$ \\
\hline 8 & $\begin{array}{l}\text { Knowledge and its role in } \\
\text { language learning. }\end{array}$ & Focus on knowledge telling when the going is rough \\
\hline 9 & Lack of methodology. & Teachers fall back on 'learning by heart' or rote learning to ensure student involvement. \\
\hline 10 & $\begin{array}{l}\text { i. Use the mother tongue. } \\
\text { ii. Use only English }\end{array}$ & Use a strict one language policy or translate \\
\hline
\end{tabular}

Table 2: Syllabus Outline for In-service Primary Education Teacher Development in Language Teaching

\section{Topics}

Form-focused activities (phonology)

Opportunities to interact more in English.

Self-reflection on professional skills.

Practice of positive thinking and self-esteem.

The importance of relaxing, play creating spaces, having fun

Strategies of learning

Discovery Learning

Open learning

Familiarisation with the basic principles of syllabuses before embarking on teaching a new syllabus or textbook..

Language Acquisition of L1 and L2; importance and impact

of bilingualism on cognitive processes

Language across the curriculum.

The skills of language; the process of language learning.

Beginning reading and writing in the classroom.

Dialogue with School administrations on the process of language learning.

Formative evaluation of progress needs more involvement and discussion.

Knowing how to go beyond the text

Knowing how to use a text

The place for recitation and rote limitations and usefulness

\section{Gaps \& Strategies}

1

1

1

5

8

8

2

$10,2,3$

8,3

6

7

9 
The strategies that teachers used, were, in turn, reformulated as areas for discussion in interactive in-service meetings with facilitators (see Table 2). This reformulation was relevant since they came from dialogue with teachers. They carried, therefore, a validity that would ensure dialogue and learning. Some strategies used by teachers could be identified as arising out of cultural orientation, the pervasiveness of which (Alexander, 2000) implies a cultural mind set and comfort zone. Chanting, repetition and rote learning, and a focus on form, for example, are all aspects that come from an oral tradition which is culturally familiar, while other orientations, like dancing, singing, watching movies or cricket matches, are all participatory, mainly as spectators. Perhaps this is why language games and such activities that originate from western cultural traditions do not end up as enormously popular among Indian teachers.

\section{DISCUSSION}

Our data analysis shows that there are gaps that the primary teacher faces, in practice. The effect that teacher competence and teacher proficiency in the language could have on the young learner is a matter of concern. Although Cummins and others do say that the initial low threshold level would change after more language is acquired and when the learner moves into the formative stages of development described by Piaget, the assumption on which this is made is that the teacher has a basic proficiency and training for development to occur.

Teachers use strategies that are often the best solution in a given situation, which includes the background and resources that a teacher has. Just as the problems identified are special to the Indian and south Asian contexts of learning, strategies of use and training also need to be suitable to the cultural set-up in which English is being learned. So maybe some of the strategies described as being used by teachers might just be the way to approach language learning in the Indian or south Asian contexts, or at least will be the orientation to employ in such contexts because of cultural familiarity. Training needs to keep options open in terms of what the average teacher considers important or plausible. Because confidence is necessary, we can take a leaf out of the book of the teachers and work with what we have. The syllabus topics arrived at might well have to change in interaction with the teacher's perezhivanie or 'lived or emotional experience'. (Mahn \& John-Steiner, 2002)

Poor preparation resulted in a dialogic interaction which, in turn, enabled teachers to change their views while giving a better idea of what constraints and contexts are involved with teaching the very young. As a result of interaction, teachers did not continue with many opinions and were at least willing to change their thinking about some areas. The data demonstrates that teachers work with a collective unconscious, or a critical and 'collective ZPD' (Moll \& Whitmore, 1993). Teachers' practice is formed or informed by a set of beliefs, the commonality of which shows that they are working within cultural understandings of what language teaching means at the early levels, and their beliefs, when articulated and discussed in groups or individually with a facilitator, can change in meaningful ways that would not occur otherwise. That is, the teacher's zone of proximal development, or ZPD, is assisted through collective discussion and endeavour. Discussion and becoming conscious of contradictions help in the understanding of policies.

\section{CONCLUSION}

Syllabus design for primary teacher education has therefore been elicited from teacher practice so that gaps and teaching strategies are evaluated for relevant syllabus design and methodology. Also, questions have been thrown up for further investigation. More needs to be done in terms of teacher interviews and observation of lessons in as many educational contexts as possible. Further, the role of different mother tongues needs to be examined in the process of ELT, but it is not enough to change policies and books without participation of the teacher and with top-down training programmes for in-service teachers. Policies without practical training infrastructure and programmes will only be half realized.

Finally, it might be interesting to speculate on what kind of a 'new' English will emerge in a few years' time. Languages are dynamic and surely the purist approach will only delay change, but there are gross difficulties in semi-lingualism where a loss of the mother tongue and a development of a 'new' English will short change children from growing cognitively to their full extent. What is the solution? The answer is intensive teacher empowerment or beginning English at a later stage? 


\section{ACKNOWLEDGEMENTS}

I would like to acknowledge the help rendered by Dr. Tara Ratnam and Ms Mousimi De in collecting data for the paper and also want to thank Prof.Rama Mathew, I. Meenalochana for reading the final draft. I thank teachers and pupils at three Kendra Vidyalya Sangatan schools in Hyderabad, India, for generously allowing me to visit their classrooms and for their interaction.

\section{NOTE}

Perezhivanie describes the affective processes through which the interactions in the ZPD are individually perceived, appropriated and represented by participants.

\section{AUTHOR INFORMATION}

Dr.Rachel Lalitha Eapen is currently teaching in the Department of English, at Sultan Qaboos University, Muscat, Oman. She has worked at The English and Foreign Language University (CIEFL), Hyderabad from 1977 to 2008, in Applied Linguistics. She has authored books for the primary level, published by Pearson Education, India. She was the Resource person for the primary school textbooks brought out by the NCERT, New Delhi in 2005-2006. E-mail: lalitha.eapen@gmail.com

\section{REFERENCES}

1. $\quad$ Alexander, R. (2000). Culture and Pedagogy. Oxford: Blackwell.

2. Bakhtin, M. (1981). Dialogic Imagination: four Essays. (V. Liapunov. Trans. And Notes,) Austin, Texas: Univ. of Texas Press.

3. Bialystok, E. (2008). Keynote address, in Proceedings of the 32nd Annual Boston University Conference on Language Development, November 2-4, 2007, edited by H. Chan, H. Jacob, E. Kapia. Cascadilla Press.

4. $\quad$ Bruner, J. S. (1961). The act of discovery. Harvard Educational Review 31 (1): 21-32.

5. Carr, M. (2002). 'Emerging Learning Narratives: A Perspective from Early Childhood Education' from Wells and Claxton. Oxford: Blackwell.

6. Cummins, J. (1979). Linguistic interdependance and the educational development of bilingual Children. Review of Educational Research. 49, 222-51.

7. Cummins, J. (2001) An Introductory reader to the Writings of Jim Cummins. Ed. Y Baker, C. and N.H. Horberger. Clevedon, UK: Multilingual Matters.

8. Graddol, D. (2005). English Next. British Council.

9. Graddol, D. (2010). English Next India. British Council.

10. Holbrook,M and V. John-Steiner. (2002). 'The Gift of Confidence: A Vygotskian View of Emotions.' From Wells and Claxton [Eds].

11. Kachru, B. (2001). Special lecture on the occasion of the conferral of Honorary fellowship of CIEFL, Hyderabad. Hyderabad:Ciefl.

12. Krashen, S.D. (1982). Principles and Practice in Second Language Acquisition. Oxford: Pergamon.

13. Mohanty, A . quoted in http://englishnext.in/9

14. Mercer, N. (2000). Developing dialogues. In Wells and Claxton (Eds.).

15. Mercer,„N, (2000). Words and Minds: How We Use Language to Think Together. London: Routledge.

16. Moll and Whitmore. (1993). Cited in Mercer (2000).

17. NCERT. (2005). Marigold. 1-5. NCERT:New Delhi

18. NCERT. (2005). The National Curriculum Framework. 2005. New Delhi: NCERT.

19. (John-Steiner and Mahn, 1996; Wells, 1999;

20. Schmidt, R. (1993). Awareness and second language acquisition. Annual Review of Applied Linguistics 13, 206226.

21. Skutnabb-Kangas,T. (1981). Bilingualism or Not: The Education of Minorities. Clevedon: Multilingual Matters.

22. Skutnabb-Kangas and Toukamma,P. (1976). Teaching migrant children's mothers tongue and learning the language of the host country in the context of the socio-cultural situation of the migrant family. Helsinki: The Finnish National Commission for UNESCO. Cited in J. Cummins (1979).

23. Viruru, R. (2003). Postcolonial perspectives on childhood and literacy. In N. Hall, J. Larson, \& J. Marsh (Eds.), Handbook of Early Childhood Literacy. London: Sage.

24. Vygotsky,L.S. (1972). Thought and Language. Cambridge, MA: MIT Press.

25. Wells G and G. Claxton. (2002).[Eds.]. Learning for Life in the 21st Century. Oxford: Blackwell. 